\title{
Rules for Radicals - 50 anos depois
}

\author{
Rules for Radicals - 50 years after
}

Carla Pinto ${ }^{1}$

\begin{abstract}
Resumo
Este artigo tem por objetivos (1) assinalar os cinquenta anos da publicação de uma das mais importantes obras sobre organização comunitária intitulada "Rules for Radicals", de Saul Alinsky; (2) deixar algumas reflexões sobre a relevância desta obra e do pensamento de Alinsky para a intervenção social na atualidade. Começamos por referir alguns apontamentos biográficos sobre Alinsky e o seu percurso de organizador comunitário, apresentamos a obra e as regras para radicais nele enunciadas e finalizamos com breves reflexões suscitadas por este livro tão controverso e pragmático.
\end{abstract}

Palavras-chave: Saul Alinsky, organização comunitária, Rules for Radicals.

\begin{abstract}
This article aims to (1) mark the fifty years since the publication of one of the most important works on community organization entitled "Rules for Radicals", by Saul Alinsky; (2) leave some reflections on the relevance of this work and Alinsky's thought for social intervention today.

We begin with some biographical notes about Alinsky and his path as a community organizer, we continue by presenting the book "Rules for radicals" and the rules set out in it, and end with brief reflections raised by this very controversial and pragmatic book.
\end{abstract}

Keywords: Saul Alinsky, community organization, Rules for Radicals.

\section{Introdução}

“Aquilo que não vacila não tem solidez” (Vladimir Holan)

Neste ano de 2021 celebram-se 50 anos da publicação da obra Rules for Radicals de Saul Alinsky. Esta obra tornou-se rapidamente no que podemos chamar um clássico da organização comunitária ${ }^{2}$, e da intervenção sociopolítica no geral. Foi controversa desde o início e tem deste então influenciado sucessivas gerações de interventores sociais e comunitários. Sentimos, portanto, a necessidade de assinalar este aniversário e (re)avivar a memória deste importante influenciador do Serviço Social. E eventualmente

\footnotetext{
${ }^{1}$ Professora Associada no CAPP/ISCSP-UL | E-mail: cpinto@iscsp.ulisboa.pt

${ }^{2}$ Seguimos neste texto a definição que Carmo et al. (2015:74) dá de organização comunitária como um "processo de articulação de meios (materiais e humanos) suscetíveis de criar condições a um determinado conjunto social para que se transforme numa comunidade."
} 
dar a conhecê-lo a gerações mais novas que ainda não tenham tido o gosto de o conhecer, e despertar a sua curiosidade para descobrirem mais sobre Alinsky.

Mas não se veja nestas intenções apenas o desejo de fazer uma nostálgica viagem ao passado, pelo contrário, queremos chamar a atenção para Alinsky e o seu Rules for Radicals porque consideramos que a mensagem desta obra tem uma relevância fundamental para os interventores sociais de hoje, e para as ações que precisam levar a cabo no enfrentamento dos desafios atuais.

Argumentamos neste artigo que para fazer face a estes desafios precisamos ser "radicais" nos nossos pensamentos, sentimentos e ações enquanto interventores sociais ${ }^{3}$ (quer sejamos assistentes sociais, animadoras sócioculturais, educadoras sociais, quer psicólogas comunitárias, sociólogas, entre outros perfis de intervenção especializada). E precisamos ser mais radicais porque a magnitude e natureza dos problemas que enfrentamos nos dias de hoje assim o exige: são problemas planetários, extremamente complexos, que envolvem a sobrevivência da espécie humana e da Terra como a conhecemos, e que exigem transformações estruturais quase totais. Não se resolvem com adaptações ou medidas superficiais, exigem que se vá "às raízes" da organização da vida humana. É este o cenário que múltiplos organismos internacionais, oficiais e nãogovernamentais, têm vindo a mostrar e a consubstanciar com evidências concretas e verificáveis (PCC, 2018, UNDP, 2020). Exigem verdadeiramente o que Beck designa de "metamorfose do mundo" (Beck 2017), uma mudança de paradigma (Pinto, 2020), ou seja, uma transformação radical.

A magnitude das mudanças necessárias é assustadora e problemática: como proceder? Todos os sistemas em movimento tendem para a inércia e para a autopreservação, portanto se almejamos mudar o sistema-mundo atual (Wallerstein, 1995) podemos contar com poderosas forças de resistência à mudança. E neste cenário, os interventores sentem-se tendencialmente impotentes para mudar, incrédulos até da possibilidade de mudança, e deste modo alimentam-se gradualmente atitudes de cinismo e fatalismo imobilista, ou críticas escapistas, que não passam do mero desabafo de palavras infrutífero.

\footnotetext{
${ }^{3}$ Este artigo é escrito com as e os profissionais de Serviço Social em mente, pois é esta a minha formação e identidade. Contudo, este artigo é elaborado numa perspetiva interdisciplinar e aberta, na qual os vários profissionais de intervenção social podem aprender uns com os outros, e neste caso é minha intenção que, mesmo quando explicitamente me refiro ao Serviço Social, outros profissionais possam recolher relevância e utilidade desta reflexão.
} 
Quando Alinsky escreve Rules for Radicals, no início dos anos 1970, a sociedade norte-americana, e o mundo em geral, também pareciam desordenados, convulsivos, em crise de valores e de instituições, vivia-se um espírito de revolução, e aconteciam efetivamente revoluções por todo o mundo, de natureza política, socioeconómica, tecnológica e cultural. Em grande parte, estas convulsões resultavam da constatação das (já na altura) crescentes desigualdades, injustiças e violações da dignidade e dos direitos humanos, bem como da crescente crise ambiental que se tornava impossível de continuar a negar. Passados cinquenta anos, em 2021, continuamos com os mesmos problemas, mas em pior $^{4}$. E é porque precisamos fazer acontecer mudanças radicais, que a vida e a obra de Alinsky nos pode orientar.

Para defendermos a nossa argumentação iremos desenvolver uma análise reflexiva teórico-conceptual, com base em revisão bibliográfica, iniciando com uma sucinta introdução biográfica a Saul Alinsly, prosseguindo com a apresentação da obra em referência e os princípios enunciados, após o que procuraremos salientar a sua relevância para a intervenção comunitária contemporânea.

\section{Quem foi Saul Alinsky}

There I've had the happiest and the worst times of my life. It's the only place on earth where I've cried. Every street has its personal joy and pain to me. When I go to watch the Cubs or the Bears play and run off on Addison Street, it isn't just that (Alinsky in Sanders, 1970, p. 11)

Saul Alinsky nasceu na cidade norte-americana de Chicago, no estado do Illinois, em 1909. Filho de imigrantes judeus russos de origens humildes, cresceu e formou-se na cidade de Chicago. É certo que se licenciou na famosa Universidade de Chicago, mas a cidade educou-o de outras formas: pela sua vida num bairro pobre e operário, pela experiência em primeira mão que teve dos problemas sociais vivenciados pela população mais vulnerável. Alinsky viveu e aprendeu como cidadão de Chicago com a história conturbada desta cidade, uma típica cidade industrial norte-americana, que viria a ser

\footnotetext{
${ }^{4}$ Dito isto, quero deixar claro que nem tudo é mau ou catastrófico na humanidade, longe disso. Em muitos aspetos, as sociedades humanas nunca estiveram tão bem globalmente, os saberes humanos atingiram níveis nunca antes alcançados, e se é certo que estes nos podem aniquilar, também serão estes que nos poderão salvar dessa aniquilação. Enfrentamos o abismo, mas também vislumbramos e criamos os meios de lhe escapar. E é por isso que podemos partilhar o espírito otimista (realista) que era apanágio de Alinsky. Agimos porque sabemos que a nossa ação muda a realidade.
} 
fortemente afetada pela Grande Depressão de 1929, pela criminalidade organizada (em especial durante a Lei da Proibição) e mais tarde pelo declínio industrial a partir dos anos 1960/70.

Saul Alinsky licenciou-se em 1926 em Arqueologia, embora também tenha cursado Sociologia, tendo sido aluno de sociólogos eminentes como Parks, Shaw e Burgess. Este último foi o seu primeiro mentor, e fê-lo interessar-se pelos fenómenos do crime e desvio (Guissé, 2010, Zamora, 2014). Como era apanágio da Escola de Chicago, Alinsky aprendeu a importância do trabalho de campo, da observação direta com as populações, do trabalho com delinquentes e comunidades marginais, nomeadamente em contexto de rua.

Já em plena Grande Depressão, Alinsky teve dificuldades em encontrar emprego como arqueólogo e, consequentemente, aproveitou uma bolsa de doutoramento em Criminologia, na sua alma mater, para estudar o crime organizado. Quando frequentava o $2^{\circ}$ ano do doutoramento, foi-lhe oferecida uma posição de criminologista para trabalhar como animador com jovens delinquentes, e mais tarde numa prisão (o estabelecimento prisional de Joliet). Deste trabalho direto com delinquentes e reclusos, torna-se cada vez mais evidente que as causas do crime estão nas condições de vida dos indivíduos e Alinsky conclui que é aí que deve intervir. Será esta a sua opção de "radicalidade" (Guissé, 2010).

Alinsky influenciou fortemente a política norte-americana, mas nunca foi um político no sentido partidário, ou representante eleito no sistema democrático representativo. Foi sobretudo um militante, um ativista da justiça social, um cidadão engajado com a mudança social, um agente político da democracia participativa e direta. Alinsky sempre se considerou um homem de esquerda, mas nunca se identificou como socialista ou comunista. E se é certo que ainda hoje o consideram um ícone ou ideólogo dos Democratas progressistas, também a direita política, nomeadamente o partido Republicano, têm usado as táticas alinskianas. Embora não concordando de todo com os objetivos de Alinsky, os "radicais" de direita reconhecem a eficácia e eficiência das suas táticas (Quinqueton, 2012).

Alinsky é atualmente conhecido pelas gerações mais jovens através das importantes figuras políticas que foram influenciadas e formadas pelo seu pensamento, nomeadamente Hillary Clinton, Barack Obama, Bernie Sanders e Alexandra OcasioCortez (já chamada de "nova versão de Saul Alinsky”). 
No final dos anos de 1960, uma jovem estudante universitária chamada Hillary Rodham, mais tarde Clinton, escolheu Alinsky para objeto da sua tese de licenciatura na Universidade de Wellesley, em 1969, intitulada "There is only the fight: an analysis of the Alinsky model" (Rodham, 1969). Para a sua tese, Hillary entrevistou Alinsky e outros ativistas a ele ligados, e fez observação de campo em áreas pobres de Chicago e em projetos de intervenção comunitária, que usavam o seu modelo de atuação.

Alinsky influenciou igualmente o futuro presidente Barack Obama ${ }^{5}$, que não conheceu Alinsky pessoalmente, mas sim os seus seguidores e colegas, e frequentou as formações para organizadores comunitários ministradas na Industrial Areas Foundation, que Alinsky co-fundou ${ }^{6}$. Obama trabalhou efetivamente em Chicago como organizador comunitário na segunda metade dos anos 1980, no Developing Community Project, e o seu trabalho como organizador comunitário radical foi continuamente usado como arma de arremesso pelos opositores republicanos.

De modo inesperado (certamente radical), Saul Alinsky morreu com 63 anos, vítima de um ataque cardíaco, em Carmel, Califórnia, onde vivia, em 1972. Longe da sua Chicago ${ }^{7}$.

\section{Saul Alinsky - o organizador comunitário}

This growing recognition on the part of the people back of the yards of Chicago that many of their problems stem from sources far removed from their own community has been one of the most fundamental developments and achievements of the Back of the Yards Neighborhood Council (Alinsky, 1984, p.33)

É praticamente impossível não deixar de apresentar Saul Alinsky como um dos pais da organização comunitária ${ }^{8}$ (Carmo et al. 2015). O seu longo percurso de atividade e de

\footnotetext{
${ }^{5}$ Obama refere explicitamente Saul Alinsky na sua recente autobiografia, "Uma terra prometida", editada em Portugal em 2020 pela Editora Objectiva.

${ }^{6}$ Alisnky co-fundou em 1940 o IAF - Industrial Areas Foundation para treinar e formar organizadores comunitários radicais e financiar o trabalho comunitário que pretendia levar a cabo. O IAF ainda hoje funciona como rede de associações e projetos comunitários, continuando a promover as lideranças locais, a formação de interventores comunitários, e proporcionando consultoria e organizadores para as entidades associadas.

${ }^{7}$ Estes são apontamentos biográficos muito breves sobre Alisnky, que teve uma vida repleta de interesse, controvérsias e momentos entusiasmantes. Remeto os leitores que desejem aprofundar a sua biografia para a obra de Von Hoffman, N. (2011). Radical: A Portrait of Saul Alinsky. ReadHowYouWant.com, bem como Guissé, 2010, Schutz \& Miller, 2015, Zamora, 2016.

${ }^{8}$ Mas gostaríamos de elucidar este lugar-comum juntando "contemporânea" à designação de organização comunitária, isto porque organizar comunidades não foi um processo inventado por Alinsky, nem por nenhum indivíduo em particular, nem é uma atividade que na sua essência seja apenas dos dias modernos.
} 
teorização na organização de comunidades começou na sua Chicago, no bairro pobre de Back of the Yards, no final dos anos 1930. Aqui criou, com outros ativistas e beneméritos, o Back of the Yards Neighborhood Council, em 1939, que ainda hoje existe, e onde juntou sindicatos, entidades religiosas, empresários e outras pessoas e organizações ligadas ao bairro. Com base nesta intervenção, e paralelamente ao seu trabalho na prisão de Joliet, Alinsky explanou a sua visão destas organizações do povo (People's Organizations), métodos de atuação e princípios de intervenção na sua primeira obra fundamental Reveille for radicals, publicada em 1946.

A perspetiva de Alinsly sobre a intervenção comunitária funda-se num profundo respeito e afeto pelas pessoas vulneráveis, pelas comunidades pobres, pelas pessoas que pouco ou nada têm. A ação comunitária de Alinsly brota de um dever de intervir no sentido de assegurar os direitos e uma vida digna a todos, mas não é uma atuação "salvífica" e paternalista. É uma ação empoderante, que promove e sustenta a autonomia das comunidades e a inevitável inutilidade dos interventores. Na visão de Alinsky, o trabalho de organização comunitária envolve fundamentalmente a criação de coligações ou alianças na comunidade, a capacitação dos elementos dessa comunidade, e em especial das suas lideranças, para travarem as próprias lutas. Em qualquer comunidade existe uma diversidade e pluralidade de partes interessadas, que podem partilhar problemas ou necessidades comuns, e simultaneamente ter perspetivas diferenciadas e até contraditórias. No modelo alinskiano, torna-se essencial identificar estas diversas partes interessadas e criar ou fortalecer ligações entre elas, uni-las em alianças que potenciem uma ação coletiva transformadora, e constituam igualmente um poder numérico capaz de forçar uma reação da parte das forças dominantes. Nas palavras de Alinsky (1989, p.111), "[c] hange comes from power, and power comes from organization. In order to act, people must get together. Power is the reason for being of organizations".

A organização da comunidade é o primeiro passo para a mudança social e para a (re)construção duma comunidade diferente daquela que existe antes da intervenção, com maior poder de agir, autónoma, mais justa e democrática (Valley, 2008). Para Alinsky, a organização comunitária é essencial para assegurar uma real democracia, onde todos tenham o Poder para participar como cidadãos de pleno direito, visto que a democracia

Todavia, o entendimento ou conceptualização do que seja organizar uma comunidade muda no espaçotempo, por isso enfatizamos neste artigo que Alinsky é uma figura fundamental para a organização comunitária como é hoje entendida (Carmo et al., 2015, Rothmann, 2013). 
representativa tem fortes limitações para contrariar as desigualdades de poder (Guissé, 2010).

A visão de Alinsky sobre o trabalho comunitário apoia-se num modo de intervir que contraria uma distinção clara entre profissionais, de fora da comunidade e que nela intervêm, e a comunidade enquanto sujeito passivo da intervenção. Esta separação, que Alinsky critica, era (e ainda será) resultado em grande parte dos esforços de profissionalização dos interventores especializados e consequente ênfase na diferenciação de competências, saberes e legitimidades de ação nas comunidades, mas que não deixam de potenciar a subalternização das populações com quem se intervém. A radicalidade de Alinsky também passa por tornar a ação dos interventores progressivamente dispensável e desnecessária. O que interessa é a autonomia e o empoderamento da comunidade e dos seus líderes, a partir do interior das comunidades, das suas forças, recursos e vontades. Deste modo, Alinsky promovia já o empoderamento coletivo, muito antes de este conceito entrar no mainstream da intervenção social (Nagels, 2019, Pinto, 2012, Zamora, 2014).

\section{Rules for Radicals - Regras para Radicais}

\section{A obra}

What does the Radical want? He wants a world in which the worth of the individual is recognized. He wants the creation of a kind of society where all of man's potentialities could be realized; a world where man could live in dignity, security, happiness and peace — a world based on a morality of mankind. (Alinsky, 1946, p. 23)

Saul Alinsky é particularmente conhecido, e citado frequentemente, pela última obra, que publicou em 1971, um ano apenas antes da sua morte, intitulada Rules for radicals (Regras para radicais), e onde aprofunda e atualiza a sua visão exposta inicialmente em Reveille for radicals. Trata-se de um "manual pragmático para radicais realistas", como se afirma no seu subtítulo. Não é uma obra teórica ou de discussão conceptual, é sobretudo um guia para a ação, um elucidar do "como fazer", através de um conjunto de regras ou táticas que devem orientar a intervenção radical.

O manual para radicais estrutura-se em nove capítulos que abrangem desde considerações iniciais sobre o propósito, reflexões sobre a escolha de meios e fins, considerações sobre as organizações e a comunicação, às várias fases de atuação, os 
primeiros passos, as táticas e exemplos concretos da sua aplicação. A obra termina com reflexões para o caminho a seguir no futuro.

Nesta obra, Alinsky começa por fazer uma comparação ao "Príncipe" de Machiavelli: se neste clássico da ciência política o autor escreve para o poderoso príncipe em como governar o Povo, Alinsky dirige-se ao Povo e diz-lhe como ganhar e usar o poder contra os "príncipes" que o oprimem" (Alinsky, 1989, p. 3).

E para tal desígnio vale (quase) tudo. Nas palavras de Alinsky, "[t]hat perennial question, "Does the end justify the means?" is meaningless as it stands; the real and only question regarding the ethics of means and ends is, and always has been, "Does this particular end justify this particular mean?” (Alinsky, 1989, p. 24). Quando as populações vulneráveis e marginalizadas lutam contra adversários muito mais poderosos, é difícil concluir pela justeza desta ou daquela ação, uma vez que essa legitimidade tende a ser vista pelos olhos dos poderosos, que se inclinam muito mais para penalizar as ações dos adversários do que as suas. E que também têm muito mais recursos e possibilidades para agirem, ao contrário das comunidades desempoderadas, que muitas vezes têm apenas o seu "grito" como arma (Carmo et al., 2015)

Embora a diferença de poder entre adversários possa ser colossal, Alinsky apresenta uma proposta que é realista e não utópica. Os radicais para quem Alinsky escreve são atuantes no aqui e agora, fazem acontecer uma nova realidade social. São coerentemente radicais nos seus pensamentos e ações, e não meramente nas palavras ou boas intenções, como os "radicais retóricos".

The Radical is that unique person who actually believes what he says. He is that person to whom the common good is the greatest personal value. He is that person who genuinely and completely believes in mankind. The Radical is so completely identified with mankind that he personally shares the pain, the injustices, and the sufferings of all his fellow men (Alinsky, 1946, p. 22-23).

O radical dedica-se, com o coração e a mente, a destruir as raízes do medo, da insegurança, da opressão, da miséria (Alinsky, 1946). É importante salientar, como o faz Alinsky, que um radical precisa aliar o seu pensamento e ideais abstratos - a mente - com as suas emoções e sentimentos - o coração - distinguindo-se deste modo dos "liberais"

\footnotetext{
${ }^{9}$ Alinsky apresenta um modelo de classes simples, a que chama de "trindade" (Alinsky, 1989, p.15): os que têm (Haves), os que não-têm (Have-nots) e os que têm-um-pouco-e-querem-mais (Have a little, want mores, a classe média).
} 
(demasiado cerebrais) e dos irrealistas/escapistas (presos nas emoções e que nunca avançam na ação concreta). O interventor radical não é um mero trabalhador especializado, pretensamente (e ilusoriamente) neutro, mas um ser humano como todos os outros com quem trabalha, partilhando as mesmas emoções básicas, medos, anseios e expectativas. E age para concretizar valores específicos e muito reais. São estes os fins que ancoram e legitimam a ação.

\section{As regras}

Mark Twain once said that an ethical man was a Christian holding four aces. If you've got that you can afford to be ethical. The ethics of means involves a lot of things, such as who is the judge, the times, and whether you're winning or 1osing. (Alinsky in Sanders, 1970, p. 55).

Alinsky enuncia treze regras que são táticas de poder e de confrontação nãoviolenta, que enunciam de que maneira "os-que-não-têm" podem tirar poder "[d]os-quetêm”. Elas são uma síntese resultante das décadas de trabalho comunitário de Alinsky e dos seus colaboradores, e dos numerosos projetos comunitários desenvolvidos, uns com mais sucesso do que outros, mas todos tendencialmente controversos na perspetiva do sistema dominante ${ }^{10}$. Qualquer mudança é como um movimento, e todo o movimento causa fricção: a mudança social causará sempre alguma fricção ou conflito social, e Alinsky procura que o interventor radical não tema esse conflito, mas o lidere, se prepare e se mantenha atento ao evoluir da ação. Como afirma Alinsky no seu manual (1989, p.63), "[c]onflict is the essential core of a free and open society. If one were to project the democratic way of life in the form of a musical score, its major theme would be the harmony of dissonance".

As táticas que Alinsky enuncia são realistas, profundamente práticas, e intensamente desestabilizadoras para os adversários. O radical que as aplica trabalha de dentro do sistema que quer transformar, e este é um aspeto extremamente importante. $\mathrm{O}$ radical de Alinsky não espera que as condições se revelem propícias, cria-as; não atua como se o sistema dominante já tivesse mudado, parte do ponto em que o sistema está; aceita a realidade que existe de modo a poder alterá-la.

\footnotetext{
${ }^{10}$ Para explorar estas inúmeras e enriquecedoras experiências de Alinsky ver as suas obras (nomeadamente 1946, 1984, 1989) e também, entre outras, Guissé, 2010, Nagels, 2018, Quinqueton, 2012, Sanders, 1970, Schutz \& Miller, 2015 e Zamora, 2016.
} 
A filosofia de ação de Alinsky não é particularmente "revolucionária", mas sobretudo "reformista", o que pretende é pressionar o sistema até chegar a um ponto de transformação. Trabalhando a partir de dentro do próprio sistema, ou seja, aproveitando as instituições e as normas, os interesses e os recursos existentes, identificando e expondo as contradições do sistema, o modelo de Alinsky procura potenciar o sucesso da mudança. Atacar o sistema a partir de fora é muito mais difícil de concretizar, o que pode eventualmente manter essas oposições apenas no domínio do debate de ideias, nas boas mas infrutíferas intenções ou na mera crítica inconsequente.

Passamos de seguida a apresentar as regras para radicais, tal como enunciadas por Alinsky (1989):

O poder não é apenas o que você tem, mas o que o inimigo pensa que você tem.

Nunca saia da experiência das pessoas com quem trabalha.

Sempre que possível, saia da experiência do inimigo.

Faça o inimigo cumprir seu próprio livro de regras.

O ridículo é a arma mais potente do homem.

Uma boa tática é aquela que as pessoas gostam.

Uma tática que se arrasta por muito tempo torna-se numa chatice.

Mantenha a pressão.

A ameaça geralmente é mais assustadora do que a própria coisa.

A principal premissa da tática é o desenvolvimento de operações que mantenham uma pressão constante sobre a oposição.

Se você empurrar um aspeto negativo com força e fundo o suficiente, ele irá transformar-se no seu contrário.

O preço de um ataque bem-sucedido é uma alternativa construtiva.

Escolha o alvo, fixe-o, personalize-o e polarize-o.

As populações excluídas e vulneráveis com as quais o interventor radical trabalha estão efetivamente numa posição de desvantagem em termos do Poder de agir face aos interesses dominantes da sociedade, possuem menos recursos materiais, financeiros e simbólicos, mas não são "sem poder". Todos os sujeitos sociais conseguem mobilizar alguma forma de poder, embora para tal possam necessitar de apoio. É nesta necessidade 
de apoio que entronca o modelo de Alinsky de organização comunitária, e as treze regras acima enunciadas.

As comunidades marginalizadas têm o poder que vem da união dos seus elementos e dos aliados nas suas lutas. Têm o Poder do número, se funcionarem de modo coletivo e organizado. Têm o Poder das suas competências, forças e talentos, a inventividade e génio humanos, as suas vontades e intenções. Contudo, é essencial que as comunidades tenham consciência desse Poder que possuem, acreditem nele e o publicitem, de modo a que os seus adversários o reconheçam e eventualmente o temam.

Para que a comunidade se sinta segura no embate contra adversários poderosos, é conveniente que as ações levadas a cabo estejam dentro das competências, experiência e cultura das pessoas, para não potenciarmos medos, confusões e inseguranças, que poriam em causa a eficácia da luta. Mas pelo contrário, será útil que se confronte o adversário fora da sua experiência, gerando precisamente medo, confusão e defesa. É igualmente fundamental que as táticas escolhidas sejam do agrado da comunidade e gerem satisfação, sobretudo porque é crucial que a comunidade esteja preparada para uma luta prolongada e contínua, e com prováveis mudanças de planos e táticas em resposta ao adversário, de modo que se esteja em controlo do processo e mantendo sempre a pressão. Alinsky enfatiza similarmente a importância de fazer o adversário jogar segundo as suas próprias regras e princípios, levando-o se possível a contradições, incongruências e descrédito caso não o façam.

O modelo de organização comunitária de Alinsky segue efetivamente uma via nãoviolenta, em termos de violência física pelo menos, contudo houve e haverá quem identifique nas táticas alinskianas alguns traços de grande violência psicológica e simbólica, designadamente a utilização da ridicularização e de um humor cáustico, que sempre foram das táticas mais receadas pelos adversários de Alinsky e mais apreciadas pelos seus colaboradores. Um dos efeitos esperados deste tipo de ação era precisamente enfurecer o adversário e levá-lo a agir de modo contrário aos seus princípios ou preceitos éticos. A pressão constante exercida sobre o adversário levando-o a cometer erros e ações negativas poderia então gerar consequências positivas para a luta da comunidade. No limite, o modelo de atuação de Alinsky leva a luta a um patamar no qual já só seria necessário ameaçar o adversário de uma possível ação para obrigar a concessões por parte deste.

As últimas duas regras, doze e treze, referem-se a duas condições elementares para o sucesso das outras táticas (elas não faziam parte da lista inicial de regras e foram 
acrescentadas já na fase de edição): o preço do sucesso é apresentar uma alternativa construtiva ao adversário, pois a luta empreendida pela comunidade tem um projeto social por detrás, não se tratando apenas de desconstruir um sistema mas de ser capaz de propor uma alternativa melhor; a outra condição é a necessidade de escolher o adversário-alvo, fixá-lo, personalizá-lo e polarizá-lo. É essencial saber quem é o inimigo, nomeá-lo, reconhecê-lo e isolá-lo, mesmo que na realidade tal signifique escolher dentre um conjunto muito alargado de pessoas e organizações com responsabilidades num problema, o que é característico das sociedades contemporâneas e dos problemas altamente complexos que enfrentam.

Estas treze táticas de obtenção e usufruto do Poder parecem-nos que continuam tão atuais como o foram na época da publicação da obra Rules for Radicals, no início dos anos 1970, na antevéspera de uma profunda crise económica e sociopolítica que denunciava (ou anunciava) a transformação da sociedade industrial e do sistema capitalista industrial num modelo de sociedade diferente, que ainda se procura concretizar nos dias de hoje.

\section{Atualidade de Saul Alinsky}

"These are the days when man has his hands on the sublime while he is up to his hips in the muck of madness" (Alinsky, 1989, p.xv)

A obra de Saul Alinsky é vasta e com uma grande extensão de influência, não cabendo neste texto, necessariamente breve, elencar todas as formas de que se reveste o seu interesse e relevância. Com esta condicionante, também não iremos contextualizar Alinsky na história, mais do que centenária (Gutiérrez e Gant, 2018), da Organização Comunitária e do Serviço Social de Comunidades ${ }^{11}$, que antecede Alinsky e o (en)forma, mas antes iremos focar a sua relação com a intervenção comunitária contemporânea.

O nosso objetivo é antes de mais identificar e refletir sobre algumas ideias que nos parecem particularmente significativas sobre a atualidade da obra de Alinsky, "Regras para radicais", no enfrentamento dos desafios que a humanidade enfrenta presentemente. A reflexão que propomos adiante está condensada na figura seguinte:

\footnotetext{
${ }^{11}$ Para os objetivos deste artigo, entendemos Serviço Social de Comunidades como uma estratégia (ou método) macro do Serviço Social, que coloca a comunidade como foco e meio da mudança social promovida pela atuação da/o assistente social (Carmo et al., 2015, Jarpa-Arriagada, 2020, Mouro, 2009).
} 
Figura n.1. Reflexão sobre o uso da "Regras para Radicais" na atualidade

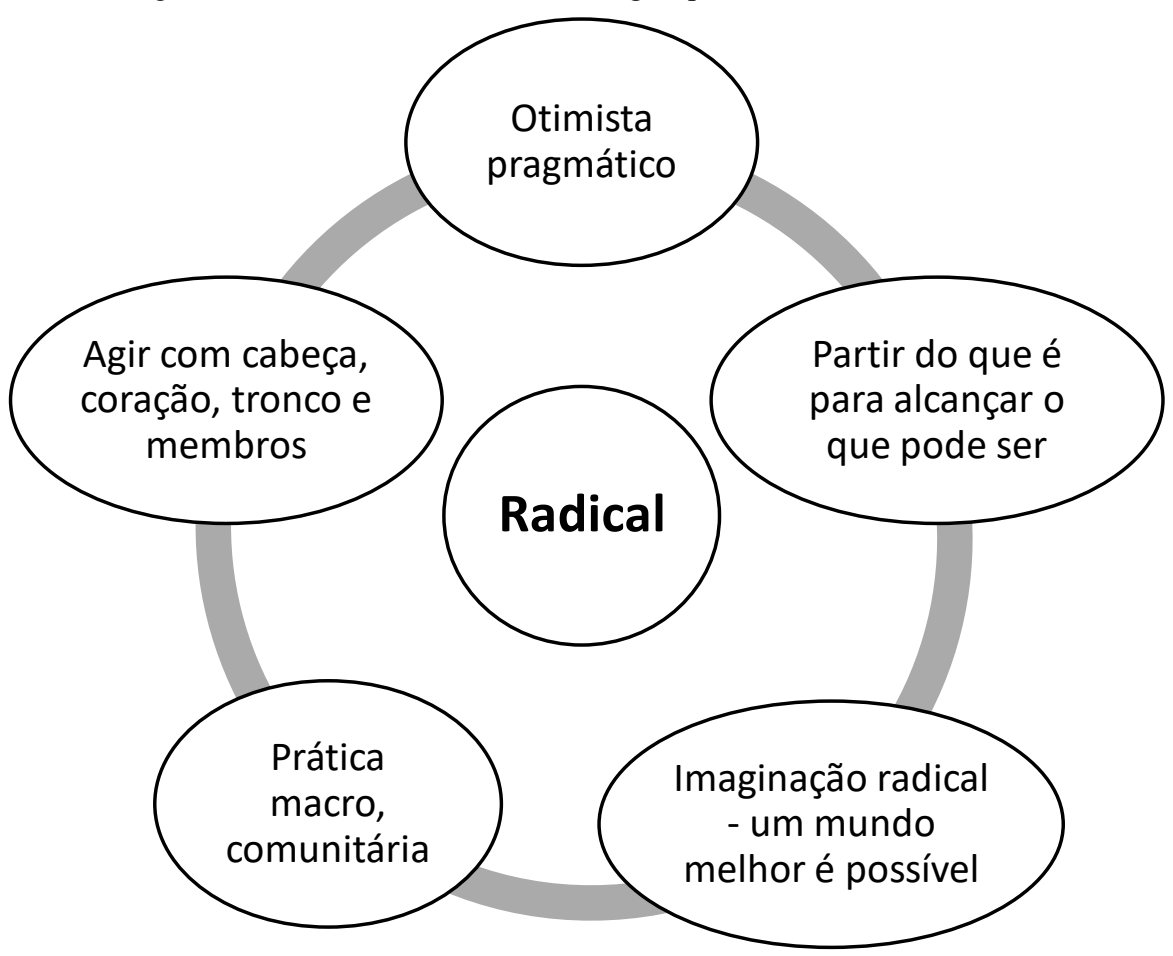

\section{Ser radical pragmático}

O primeiro aspeto que é necessário referir é o próprio termo "radical”. Associamos hoje em dia muito mais facilmente o termo radical a extremismo, violência, intolerância antissistema, do que à procura do essencial ou raiz dos fenómenos. A definição que Alinsky dá de radical volta a centrar esta palavra na sua origem etimológica, Radix (Lat.) = Raiz. Radical significa também "inerente", "inseparável" e "completo". O radical de Alinsky é alguém profundamente empenhado e envolvido na procura dos valores humanistas básicos, as raízes do viver social: a justiça, a dignidade, a liberdade, a igualdade e a solidariedade ${ }^{12}$. Os problemas de pobreza, exclusão, discriminação e opressão que as comunidades vulneráveis experienciam resultam da violação destes valores pelas estruturas e instituições sociais dominantes, e como tal, se não atuarmos a este nível, os problemas das comunidades não serão resolvidos, mas, na melhor das hipóteses, atenuados ou camuflados (Dominelli e Campling, 2002, Jarpa-Arriagada, 2020, Mouro, 2014).

Outro aspeto importante é que o interventor radical não trabalha de fora do sistema mas de dentro. Não é necessariamente um outcast, um marginal, mas alguém que sabe

\footnotetext{
12 Os conceitos, princípios e modos de Alinsky não são em si mesmos necessariamente novos ou inéditos, podemos identificá-los claramente a partir do século XIX (se não quisermos ir mais longe), mas a sua autenticidade, criatividade e carisma fazem de Alinsky uma figura incontornável e única.
} 
falar as linguagens do sistema, que desempenha papéis relevantes ao sistema. É o que se passa com a clara maioria dos profissionais de Serviço Social (e outros interventores sociais), os seus postos de trabalho fazem parte do sistema de proteção social instituído e das políticas públicas sociais (Carvalho, 2020). Ser radical não é forçosamente destruir o sistema, mas sim melhorá-lo, reformá-lo, transformá-lo (Ardle, 2020). Como afirma Ardle (2020), ser radical passa pela capacidade de "balançar o barco estando nele", que foi precisamente o que Alinsky fez.

Para isso ser possível é crucial que o interventor radical seja pragmático, bem enraizado na realidade dos fenómenos, concreto nas suas ideias e projetos, qualificado nos seus saberes e competências. E igualmente otimista, uma vez que sem otimismo, sem esperança e crença na mudança, não haverá razões para intervir. Tal era a filosofia pessoal de Alinsky (1989, p.17).

\section{Partir do que é, para alcançar o que pode ser}

Ser realista é imprescindível para o modelo de Alinsky. É primeiro necessário aceitar a realidade como ela é, para depois a poder mudar. Daqui resulta a importância central da compreensão da realidade das comunidades e das pessoas vulneráveis. Isto significa nomeadamente:

- Capacidade para elaborar colaborativamente avaliações diagnósticas, participativas e emancipatórias, capazes de promover a Voz das pessoas e das comunidades vulneráveis e a sua autonomia;

- Não nos limitarmos a uma recolha de informação e análise superficiais das realidades complexas vividas no seio das comunidades, mas procurarmos descobrir as causas-raiz que alimentam a injustiça e a miséria. $O$ ser radical implica ter capacidade crítica, pôr em questão, analisar axiologicamente a realidade. Trata-se de seguir o famoso método Ver-Julgar-Agir do Cardeal Cardijn ${ }^{13}$ (Sands, 2018);

-E para se ser crítico também é preciso ser-se curioso, querer saber "porquê", colocar em dúvida, exigir respostas e sentidos. Curiosidade igualmente em relação às comunidades e às pessoas que as formam, como sinal de autêntico respeito e consideração.

\footnotetext{
${ }^{13}$ Método seguido inicialmente pelo Movimento da Juventude Operária Cristã, em tempos de Concílio Vaticano II, e que se sedimentou como modo de atuação de muitos projetos de ação social católica (Sands, 2018).
} 
A centralidade de um entendimento profundo das realidades vividas pelas comunidades e populações mais vulneráveis entronca nas dimensões educativa e de pesquisa dos profissionais de intervenção social. As/os assistentes sociais precisam estar numa permanente busca de crescimento pessoal e profissional, de qualificação de saberes e de desenvolvimento de uma postura de pesquisa sobre o campo de intervenção profissional. Ser radical não se coaduna com amadorismos voluntaristas na intervenção, nem com saberes e competências parados no tempo (Carvalho, 2020, Mouro, 2009)

\section{Imaginar "outro mundo possível"}

Uma vez empenhados na mudança, e com o retrato mais completo possível da realidade que pretendemos mudar, então é essencial saber para onde vamos e como chegar lá. O radical de Alinsky não se limita a desconstruir/destruir o sistema: (re)constrói, tem alternativas concretas que apresenta. $\mathrm{O}$ interventor radical sabe imaginar outra versão do mundo.

O conceito de imaginação parece-nos ser aqui particularmente relevante. Para Bloch (1986), a imaginação é como um sonho para a frente, uma utopia concreta. Já para Castoriadis (1998), o imaginário social instituinte torna a mudança histórico-social possível. Mas falamos aqui de uma imaginação forçosamente radical, no sentido que temos vindo a refletir. Haiven e Khasnabish (2010) defendem que precisamos de uma imaginação radical para podermos alcançar mudanças radicais, de outro modo estaremos a reproduzir, com pequenas alterações, o sistema atual. Só uma imaginação radical nos pode levar a novos "horizontes de possibilidades sociopolíticas" (idem, p. iii).

A imaginação radical, à semelhança da "imaginação sociológica", leva-nos a ter uma outra visão sobre a realidade, diferente do senso comum (Rethmman, 2010). Embora a imaginação tenha raízes na experiência dos sujeitos, nas suas vidas, é nesta perceção da realidade vivida que tomam forma as possibilidades de mudança, as alternativas ao vivido, ao que é potencial, possível, mesmo que ainda inédito (Paulson, 2010). Segundo Paulson (2010), esta é a grande diferença entre uma imaginação não radical e a radical, pois que a não radical não sai dos limites do vivido e do conhecido. Atua segundo o mote "não há alternativa".

Só conseguimos ir mais além se navegarmos sem ser à vista. Precisamos de nos abrir ao diferente, ao radicalmente Outro e às suas vivências. Como salienta Larina Lai (2010), as dificuldades em imaginar outra realidade possível (e desejável) podem ser ilustradas pela atratividade do retorno a tempos passados, estruturas e modos de vida. Podemos observar isto quer nos movimentos de extrema-direita, quer de extrema- 
esquerda, e até ligados a certas visões de resposta aos desafios ambientais. Para todos eles a solução é retornar a um passado (mítico) onde não se encontrariam os problemas de hoje. Trata-se, pois, de uma forma de escapismo.

Precisamos de uma imaginação radical para concebermos e construirmos uma outra realidade, que não se alcança pela mera transformação ou adaptação do sistema industrial e do capitalismo especulativo globalizado. Outro mundo tem de ser possível, capaz de regenerar e reformar (Taiaiake, 2010) as relações da biosfera terrestre. Não aceitar o "Não há alternativa", dogma do neoliberalismo global ${ }^{14}$, mas imaginar um mundo diferente, mas não utópico, um "inédito viável” como lhe chamou Paulo Freire (2014), e agir para o concretizar, é isto o que significa ser radical (Freire, 1987, 2014, Ferguson, 2009).

\section{Prática comunitária, prática macro}

Se estamos a pensar e a atuar ao nível da transformação social, e não meramente da terapêutica e da adaptação individual, então ser radical é privilegiar uma prática de intervenção macro, nas comunidades e sobre as políticas públicas (Carmo et al., 2015, Gonçalves, 2019, Mouro, 2009, 2014).

Isto significa reavivar a dimensão de trabalho comunitário e sociopolítico na prática do Serviço Social que, embora sempre presente ${ }^{15}$, perdeu terreno face às abordagens mais individualizantes, a partir dos anos 80 do século passado, com os avanços do neoliberalismo e do New Public Management. Desde então, as políticas neoliberais globalizadas privilegiaram medidas sociais individuais, atomizando e isolando indivíduos e comunidades vulneráveis (Karagkounis, 2021, Raichelis e Arregui, 2021). Todavia, a partir dos anos 2010, no seguimento da crise financeira global de 2008 e da consciencialização dos efeitos nefastos das políticas de austeridade, e de igual modo a crescente visibilidade dos desafios ambientais e migratórios, temos vindo a assistir a uma

\footnotetext{
${ }^{14}$ Uma ideologia de mercado que defende a crença de não existir alternativa ao mercado livre e ao capitalismo especulativo.

$15 \mathrm{O}$ trabalho comunitário moderno tem as suas raízes históricas em vários movimentos filosóficos, sociopolíticos, e até teológicos, que foram crescendo na sociedade industrial, contudo é de salientar a ligação umbilical que sempre manteve com o desenvolvimento da profissão (e disciplina) do Serviço Social, desde os finais do século XIX, nomeadamente com o movimento das Settlement Houses (Gonçalves, 2019, Mouro, 2014). Os primeiros ensaios teóricos do Serviço Social de Comunidades, com maturidade, aparecem na década de 1930, mesmo durante um período de forte implementação da corrente psicodinâmica, e a partir do pós-II Guerra Mundial e durante a década de 1950, consolida-se como método do Serviço Social, acompanhando o conceito de desenvolvimento comunitário (Ross e Lappin, 1955, Younghusband, 1959). Os anos 60 e 70 ainda são de expansão, em grande parte alimentada cientificamente pelas abordagens sistémicas, por um lado, e estruturalistas, marxistas e críticas, por outro. As lutas pelos direitos cívicos, políticos e sociais, bem como os processos de descolonização, também suportam visões comunitárias. Contudo, na segunda metade dos anos 70, com o eclodir da denominada "crise do Estado Providência", o interesse pela intervenção comunitária sofre um sério revés.
} 
renovação e ressurgimento do trabalho comunitário e sociopolítico, e uma revalorização da ação coletiva, um pouco por todo o planeta. Esta é a base de muitos dos novos movimentos sociais de promoção de alternativas ao modelo neoliberal e ao capitalismo financeiro especulativo, entendidos como fonte dos problemas ambientais e da crescente desigualdade socioeconómica. (Esgaio, 2014, Mackinnon, 2009, Reisch, 2016, Rothman, 2013).

Este ressurgimento da intervenção macro não deve ser entendido como uma desvalorização, ou mesmo a rejeição, da intervenção mais individualizada, pelo contrário trata-se de enfatizar a necessária integração dos vários níveis de atuação social. Temos necessidade de revalidar o trabalho comunitário porque encontramos consistentemente evidências da secundarização da intervenção macro na prática, educação e investigação, nomeadamente no Serviço Social (Carvalho, 2020, Flynn, 2017, Gonçalves, 2019, McBeath, 2016, Moyo, 2018).

Ao enfatizarmos a dimensão comunitária, mesmo que articulada com outras dimensões, estamos a evidenciar a importância da ação coletiva e da pertença a múltiplos coletivos, que é essencial para a concretização dos propósitos de justiça social, direitos humanos e desenvolvimento. Todavia, é necessário ressaltar igualmente que o entendimento do que seja uma "comunidade" ou mais ainda "intervenção comunitária" ou "serviço social de comunidades", é um campo de discussão, debate e posicionamentos diversos, que precisam de ser devidamente contextualizados e assumidos (Rothman, 2007). Em particular, parece-nos fundamental alertar para a possibilidade de a dimensão comunitária, tal como qualquer outra, não ser por si mesma garante de participação, justiça ou empoderamento. A intervenção comunitária tanto pode ser implementada com objetivos de normalização e controlo, como com objetivos de emancipação e empoderamento (Dominelli e Camplin,2002, Gonçalves, 2019, Jarpa-Arrigada, 2020, Mouro, 2014). O profissional radical encontra-se neste contínuo (mais do que dicotomia) Emancipação vs. Controlo, e necessita de uma permanente "vigilância epistemológica reflexiva-crítica" dos seus saberes, competências, preconceitos e relações de poder (Jarpa-Arrigada, 2020:310). Esta vigilância não é uma mera tarefa individual do profissional, mas sim coletiva da profissão, em conjunto com as/os colegas, e muito particularmente com as comunidades com quem trabalha.

\section{Agir com cabeça e coração...tronco e membros}

Ardle (2020, p.18) define um interventor comunitário radical como "grounded individual, anchored by a clean analysis and value base and a strong connection to the 
communities with which they work”. Ser radical é estar por inteiro na intervenção, isto é, mente e corpo, ideias e emoções, valores e competências (Duarte, 2018). A intervenção radical não implica somente ideias ou reflexões e coerentes construções teóricas; envolve emoções, sentimentos, traços de personalidade, o passado do interventor, feridas emocionais antigas e recentes, conscientes e inconscientes. As táticas radicais de Alinsky não raro envolviam até prosaicas funções corporais, o corpo como verdadeira ferramenta de trabalho, que é necessário cuidar, regenerar e robustecer (Alinsky, 1984, 1989, Sanders, 1970).

Para manter a perseverança, empenhamento, resiliência e resistência exigidos a um interventor radical, torna-se necessário cultivar a inteligência emocional e a inteligência espiritual, tanto como cultivar uma contínua formação teórica e operativa (Duarte, 2018). Parece-nos que o profissional radical não pode ter pruridos em assumir a sua própria vulnerabilidade e necessidade de ser cuidado, não somente através do autocuidado, mas também por meio de dispositivos profissionais, comunitários e societais de suporte e validação, e sobretudo por condições de formação e de trabalho dignas e sustentáveis.

\section{Conclusão}

Ser radical não é uma missão impossível, embora pareça. Múltiplos obstáculos, fragilidades e ameaças se levantam constantemente. Os poderes instituídos são por vezes esmagadores. Mas ser radical é precisamente saber que é possível sê-lo, que é possível fazer a diferença na procura dos valores humanistas que nos norteiam.

Vivemos tempos que reclamam interventores sociais radicais, capazes de imaginar uma outra realidade e de se empenharem na sua construção. Particularmente no âmbito do Serviço Social, profissão que se define como uma prática (e uma disciplina) que visa a mudança social e o desenvolvimento, o empoderamento e a emancipação das pessoas e comunidades, com base nos princípios da justiça social, direitos humanos, responsabilidade coletiva e respeito pela diversidade, parece-nos que o ser radical, no sentido que procurámos evidenciar, é uma questão de autenticidade das/os assistentes sociais contemporâneos. E como tal, um desafio verdadeiramente ontológico para a profissão, no âmbito da transformação social global, que assegure continuada relevância social, reconhecimento e legitimidade à sua atuação.

Rules for Radicals de Saul Alinsky faz meio século, mas continua a ser um manual de princípios e táticas pragmáticas e úteis, continua a dizer como fazer. Haja profissionais que queiram aprender com ele, e se ponham a caminho. 


\section{Referências bibliográficas}

Agência Europeia do Ambiente. (2019). O ambiente na Europa: Estado e perspetivas 2020. Serviço das Publicações da União Europeia.

Alinsky, S. (1984). Community Analysis and Organizations. Clinical Sociology Review, 2(1), 6. Reprinted from the American Journal of Sociology 46, 797-808.

Alinsky, S. (1989). Rules for radicals: A practical primer for realistic radicals. Vintage.

Alinsky, S. (2010). Reveille for radicals. Vintage.

Ardle, O. M. (2020). Rocking the boat while staying in it: connecting ends and means in radical community work. Community Development Journal.

Beck, U. (2017). A metamorfose do mundo - como as alterações climáticas estão a trasnformar a sociedade. Edições 70.

Bloch, E. (1986). The principle of hope (Vol. 1). MA| MIT Press.

Boetto, H. (2017). A transformative eco-social model: Challenging modernist assumptions in social work. British Journal of Social Work, 47(1), 48-67.

Carmo, H. (Coord.), Esgaio, A., Pinto, C., Pinto, P. (2015). Desenvolvimento Comunitário. ISCSP. Pactor.

Carvalho, M.I. (Coord.) (2020). Ser assistente social - retrato(s) da profissão. libros.

Castoriadis, C. (1998). Hecho y por hacer. Pensar la imaginación. Enclave de

Dominelli, L., \& Campling, J. (2002). Anti oppressive social work theory and practice. Macmillan international higher education.

Duarte, C. P. P. (2018). Inteligência emocional e inteligência espiritual: contributos para a humanização do Serviço Social numa sociedade em mudança [Tese de doutoramento em serviço social do ISCSP/UL].

Esgaio, A. (2014). A intervenção comunitária na prática do Serviço Social: um imperativo na conjuntura socioeconómica atual? In Carvalho, M.I \& Pinto, C. (coords.). Serviço social. Teorias e práticas, pp.205-223. Pactor.

Ferguson, I. (2009). Another social work is possible! Reclaiming the radical tradition. Theories and methods of social work: Exploring different perspectives, 81-98.

Flynn, M. (2017). Towards an environmentally-informed social work in Portugal: Anchoring sustainable paradigms for social work practice in the community. Dissertation for Erasmus Mundus Master Degree in Advanced development in social work: ISCSP/Universidade de Lisboa.

Freire, P. (1987). Pedagogia do Oprimido. $17^{\mathrm{a}}$ edição. Paz e Terra.

Freire, P. (2014). Pedagogia da esperança: um reencontro com a pedagogia do oprimido. Paz e Terra.

Gonçalves, H. J. D. C. F. (2019). Reconfiguração do serviço social contemporâneo no quadro do pensamento neoliberal. [Tese de doutoramento do ISCTE-IUL]. 
Gramsci, A. (2011). Prison Notebooks Volume 2 (Vol. 2). Columbia University Press.

Guissé, S. (2010). Saul Alinsky, Hillary Clinton et Barack Obama: de l'heritage a la realite du systeme americain. [Master dissertation. Université Stendhal Grenoble].

Gutiérrez, L. M., \& Gant, L. M. (2018). Community practice in social work: Reflections on its first century and directions for the future. Social Service Review, 92(4), 617-646.

Haiven, Max and Alex Khasnabish, "What is Radial Imagination? A Special Issue." Affinities: A Journal of Radical Theory, Culture, and Action, Volume 4, Number 2, Fall 2010, i-xxxvii.

Horton, M., \& Freire, P. (1990). We make the road by walking: Conversations on education and social change. Temple University Press.

Jarpa-Arriagada, C. G. (2020). Practices of resistance and community social work: struggles and tensions in the face of the logics of domination of the colonial and capitalist model. Revista eleuthera, 22(2), 309-326.

Kamali, M. and Jönsson, J.H. (2019) Editorial: revolutionary social work: promoting sustainable justice, Critical and Radical Social Work, vol 7, no 3, 293-314.

Karagkounis, V. (2021). Austerity, social work and the rediscovery of community work. European Journal of Social Work, 24(2), 278-289.

Khasnabish, D. A., \& Haiven, M. (2014). The radical imagination: Social movement research in the age of austerity. Zed Books Ltd.

Lai, L. (2010). Other Presents: Imagining the Human and Beyond, Affinities: A Journal of Radical Theory, Culture, and Action, Volume 4, Number 2, Fall, pp. 28-32.

Leskošek, V. (Dir.) (2009). Theories and methods of social work: Exploring different perspectives. University of Ljubljana, Faculty of Social Work.

MacKinnon, S. T. (2009). Social work intellectuals in the twenty-first century: Critical social theory, critical social work and public engagement. Social Work Education, 28(5), 512-527.

Martínez, M. J. (2005). Modelos teóricos del trabajo social. Diego Marín.

Matthies, A. L., \& Närhi, K. (. (2016). The Ecosocial Transition of Societies: The contribution of social work and social policy. Taylor \& Francis.

Mouro, H. (2009). Serviço Social e Modelos de intervenção da sociedade industrial à sociedade do risco. [Tese de doutoramento, Universidade do Porto].

Mouro, H. (2013). Estruturalismo, Pós Estruturalismo e Intervenção Comunitária. Revista Espacios Transnacionales [En línea] No. 1.2013, 82-90. http://www.espaciostransnacionales.org/reflexiones/

Moyo, L. (2018). Unlocking a paradigm shift:practitiioners' perpsectives on sustainable environment and social work in Zimbabwe. dissertação de mestrado ErasmusMundus Advanced development in social work: ISCSP - Universidade de Lisboa.

Nagels, M. (2018). Former des radicaux libres. Relire Saul Alinsky, cinquante ans après le «Manuel de l'animateur social». In Éducations critiques et épistémologies des Suds: Paulo Freire et les pédagogies alternatives, libertaires, transformatrices. 
Paulson, J. (2010). The Uneven Development of Radical Imagination, „Iffinities: A Journal of Radical Theory, Culture, and Action, Volume 4, Number 2, Fall 2010, 33-38.

PCC. (2018). Summary for Policymakers. In: Global Warming of $1.5^{\circ}$ C. An IPCC Special Report on the impacts of global warming of $1.5^{\circ} \mathrm{C}$ above pre-industrial levels and related global greenhouse gas emission pathways. World Meteorological Organization.

Pinto, C. (2012). Representações e práticas do Empowerment nos trabalhadores sociais. [Tese de Doutoramento em Ciências Sociais, especialização em Política Social. ISCSP, Universidade de Lisboa].

Pinto, C. (2014). Serviço social e desenvolvimento sustentável: missões entrecruzadas. Iin Carvalho, M.I. \& Pinto, C. (Coords.). Serviço Social. Teorias e práticas (pp.143-162). Pactor.

Pinto, C. (2020). Alterações climáticas e Serviço Social. In Carvalho, M.I. (Coord.). Serviço Social em catástrofes (pp. 107-127). Pactor.

Quinqueton, T. (2012). Saul Alinsky, le conflit et la communauté à la source de l'intégration démocratique. Vie sociale, (2), 111-128.

Raichelis, R., \& Arregui, C. C. (2021). O trabalho no fio da navalha: nova morfologia no Serviço Social em tempos de devastação e pandemia. Serviço Social \& Sociedade, 134-152.

Reisch, M. (2016). Why macro practice matters. Journal of Social Work Education, 52(3), 258-268.

Rethmann, P.(2010). A Few Notes on the Question, What is Radical Imagination. Affinities: A Journal of Radical Theory, Culture, and Action, Volume 4, Number 2, Fall 2010, 48-54.

Rodham, H. (1969). There Is Only the Fight: An Analysis of the Alinsky Model. Senior thesis, Wellesley College.

Ross, M. G., \& Lappin, B. W. (1955). Community organization: Theory and principles (No. HV40 R68). Harper.

Rothman, J. (2007). Multi modes of intervention at the macro level. Journal of Community Practice, 15(4), 11-40.

Rothman, J. (2013). Education for macro intervention: A survey of problems and prospects. https://www.acosa.org/ joomla/pdf/RothmanReportRevisedJune2013.pdf

Sanders, M. K. (1970). The professional radical: Conversations with saul alinsky. Perennial Library.

Sands, J. (2018). Introducing Cardinal Cardijn's See-Judge-Act as an Interdisciplinary Method to Move Theory into Practice. Religions, 9(4), 129.

Schutz, A., \& Miller, M. (Eds.). (2015). People power: The community organizing tradition of Saul Alinsky. Vanderbilt University Press.

Taiaiake, Alfred, "What is Radial Imagination? Indigenous Struggles in Canada," Affinities: A Journal of Radical Theory, Culture, and Action, Volume 4, Number 2, Fall 2010, 5-8.

UNDP (2020). The next frontier - Human development and the Anthropocene. UNDP. 
Valley, C. (2008). Alinsky at 100. Journal of Community Practice, Vol. 16(4), 527532.

Wallerstein, I. M. (1995s). La reestructuración capitalista y el sistema-mundo. Fernand Braudel Center for the Study of Economies, Historical Systems, and Civilizations, State University of New York at Binghamton.

Younghusband, E. L. (1959). Report of the Working Party on Social Workers in the Local Authority Health and Welfare Services. Report of the Working Party on Social Workers in the Local Authority Health and Welfare Services.

Zamora, D. (2011). Saul Alinsky: organiser les dépossédés. Rapports sociaux, de la théorie à la pratique. Raison présente, 178(1), 35-46.

Zamora, D. (2014). Saul Alinsky et les sociologues de Chicago. Esquisse d'une sociologie contestataire au temps de la Grande Dépression. Revue de l'Institut de Sociologie, (84), 25-42.

Zamora, D. (Dir.) (2016). Saul Alinsky: organiser et armer la communauté. Institut de Sociologie de l'Université libre de Bruxelles. 